\title{
The Exploration and Practice for the College Physics Experiment Teaching Mode Based on Autonomous Learning
}

\author{
Ping Wei, Minghui Shao \\ School of Physics and Technology, University of Jinan, \\ Jinan, Shandong Province, P.R. China, 250022 \\ ss_weip@ujn.edu.cn
}

\begin{abstract}
To solve the problems of bad effect of college physics experiment preparation, insufficient experimental class time, and poor active learning ability, the college physics experiment teaching mode based on autonomous learning is further investigated in this paper. During the teaching process, full use of modern information technology, reasonable instructional design, and the "microclassroom + experiment supermarket" new teaching mode for teaching college physics experiment, can improve the learning enthusiasm and efficiency of students, enhance the students' ability for autonomous learning and the ability to solve practical problems, and truly reflect the student-oriented teaching philosophy.
\end{abstract}

Keywords—College physics experiment;Micro-classroom;Autonomous learning

\section{INTRODUCTION}

The college physics experiment course is one of the important courses for the basic training of students in science and engineering. It is one of the practical courses that students have come into contact with university earlier. It is an important foundation for cultivating students' scientific experiment ability and improving scientific quality.[1] There are some problems that need to be solved in the course of traditional experimental teaching[2], including: (1) the number of students is big, the conditions of laboratory resources are limited, and the effect of college physics experiment preparation is poor; (2) the effective learning time of students is limited, and the students' understanding and mastery of the experimental principles and experimental methods is not deep and thorough; (3) traditional experimental class approach is single, and it is not conducive to students personalized teaching. (4) the enthusiasm for active learning of students is not high. These problems have long plagued the teaching of physics experiment courses. To this end, from 2014, we take " micro-classroom + experimental supermarket" new experimental teaching mode in the college physics experiment course teaching. The new teaching mode aims to improve students' autonomous learning ability, and highlight the student-centered teaching idea, so that students really become the master of experimental learning.

\section{THE CONSTRUCTION OF MICRO-COURSE RESOURCES IN COLLEGE PHYSICS EXPERIMENT}

Choosing and developing the appropriate micro-curriculum resources has a great help for students to understand the content of the course and succeed in completing the experiment. In our university, the physics experiment course is divided into two semesters, including basic experiments, mechanical experiments, thermal experiments, electromagnetic experiments, optical experiments and modern physics experiments. Each part of the content consists of specific experimental projects, the college physics experiment center opened more than 20 experimental projects each school year. The teaching content include college physics course experiment principle, the operation of the instrument, the measurement data, analysis results, error calculation and experimental report writing, and other aspects [3]. Each important or difficult part of the content of the experiment teaching is prominent, and the structure is clear, so these features facilitate the micro-course design and production. Based on this, the students from different professions can choose experimental programs according to their professional training programs and professional characteristics.

The important purpose of micro-course development is to assist students to learn experimental knowledge and experimental skills. Therefore, the content of micro-course not only includes the video data of the experimental operation demonstration process in real experiment, but also the experimental demonstration animation and teaching PPT, so that micro-course content is very rich. We split the knowledge points of a experimental project, and record shooting experimental introduction, experimental principles, experimental methods, experimental instruments, experimental operations, data processing, precautions and other different types of micro-video. We establish the college physics experiment video library, and all micro-video are placed on the school's course website. In order to facilitate students to self-study, we give each video a configured two-dimensional code. To ensure that the student's attention is not scattered, the time of each video is controlled within 10 minutes. Take the sound velocity measurement experiment as an example, a total of 10 micro-video shootings, including one video for the experimental preface, one video for the description of the measurement method, three videos for the experimental principle of (transducer working principle, phase comparison method principle, resonance interference method principle), two videos for the instrument introduction (sound 
velocity tester and oscilloscope), one video for note, and two videos for the data processing methods (difference method and least squares method).

In order to provide students with a variety of independent learning resources, in addition to micro-courses, there are other related teaching resources, in the form of animation, documents and other forms on the website, such as experimental equipment simulation, experimental report templates, experimental development and so on. Students are free to choose to read. All the microcourses are corresponding to the experimental guide materials on the two-dimensional code, and students can use the phone "sweep-sweep" function scan two-dimensional code link, directly into the corresponding knowledge point of learning. For example, students will learn the experimental principle of the experimental project" the measurement of the speed of sound ", then the student can find the experimental instructions corresponding to the experimental project scanning experimental principle introduced next to the two-dimensional code (shown in Figure 1), into the experiment course site page, he/she can click on the video to play, directly into the Micro-course video interface (shown in Figure 2)[3]. Students can control the progress of their play according to their own learning needs. So every student can scan two-dimensional code for each content of learning at any time.

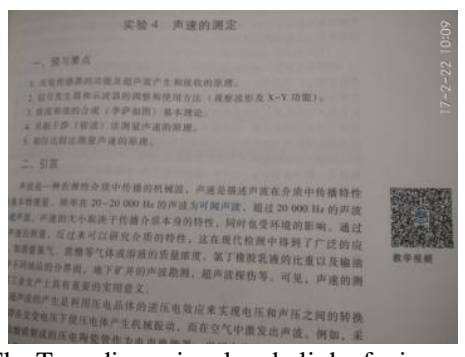

Fig. 1. The Two-dimensional code link of micro-course

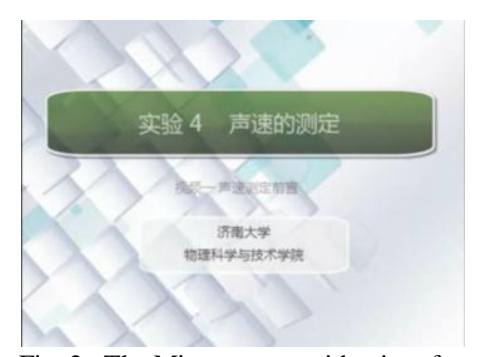

Fig. 2. The Micro-course video interface

Through the study of micro-course of college physics experiment, students can choose their own learning resources and learning time according to their own needs, obtain knowledge and guidance in and out the classroom, and make up for the deficiency of classroom teaching mode of traditional experimental course. So, the students have a good autonomous learning environment.

\section{THE EXPLORATION AND PRACTICE OF TEACHING MODE BASED ON AUTONOMOUS LEARNING}

\section{A. The construction of "experimental supermarket"}

The micro-course is widely used in the teaching of physics experiment in our university, which not only improves the students ' effect of preparation for the experimental course, but also improves the ability and interest of students' autonomous-learning. To further improve the ability of students to self-study, we have adopted the "micro-classroom + experimental supermarket" teaching mode. This kind of teaching mode has carried on the big reform to the traditional experiment teaching way. In order to realize the "supermarket" function of the laboratory, each laboratory has all the experimental items (usually 10-12 items) to be carried out in the semester, Each experimental project is equipped with 2 sets of experimental equipment, a total of 20-24 sets of experimental equipment, and all the experimental projects opened in a semester are completed in the same laboratory. The establishment of "the experimental supermarket" completely solve some problems existing in the traditional single laboratory, and it provides more convenience to teachers and students, respectively.

"Experimental supermarket" makes the students do experiment very freely. The establishment of the experimental supermarket completely solve some problems of the traditional single laboratory, and provide more convenience for the teachers and students. "Experimental supermarket" makes the students do experiment very freely. In the experimental supermarket, students can choose six experimental projects according to their own profession and interest, and independently complete all the experimental content. In the course of the experiment, students have not any restrictions, and can advanced learn, repeated practice any one of the experimental projects set up in the laboratory. Students who have learned corresponding skills can also expand their existing projects. In order to improve students' experimental skills and develop students' innovative ability, teachers can also increase the election project and innovative projects based on the professional characteristics of students. This kind of teaching mode, not only improves the students' experimental operation skills, but also promotes the students' ability for independently learning and innovation.

\section{B. The practice of the new teaching mode}

The new teaching mode based on autonomous learning idea greatly changes the traditional teaching mode. The teacher in the classroom no longer teach the experimental principles, operation steps and other aspects, and the students become the master of the classroom[5]. The students self-study through a large number of teaching resources provided by teachers, while 
the main tasks of teachers are organization and management of the class, instruction for students, and some laboratory maintenance work.

The process of "experimental supermarket" teaching mode is the same as that of traditional experiment teaching method. It is divided into three stages: before the experiment, experiment and after the experiment[6], but the actual operation has changed greatly (as shown in Table 1). The new teaching mode also enhances the requirements of the experimental instructors. On the one hand, the experimental teachers are required to master all the experimental items that may be set up in the experimental supermarkets in this semester. On the other hand, all the experimental data ( Micro-course video, experimental report templates, experimental courseware and handouts, etc.) are need to release to the course site. In this teaching mode, students are required to completely self-study. Each time the students need to watch the experimental microcourses (experimental principles, instrument introduction, precautions, etc.) and related information, and fill out the experimental preview report before the experiment. In order to improve the students 'ability of autonomous learning and improve the efficiency of students' learning experiment, the teachers of the experimental center have set up the corresponding preview report template for each experiment, and use the problem-oriented preview in the preview report template (set up some questions, ask students to watch micro-video). When the students meet the teachers' corresponding request, they can start the experiment. In the classroom, the traditional way is the teacher to explain the experimental principle in detail, to demonstrate the experimental operation process, and then students begin to do the experiment. In the new class approach, the experimental instructors no longer explain the principles and operations of the experiment, and the teacher's main task is to check the student's preview condition. They give the effective guidance according to the problems encountered by each group of students in the course. In order to deepen the students' understanding of the experimental principle and experimental methods, the mastery of the instrument using method, the group discussion is added in the course of the experiment. After the experiment, the teacher through the question or group discussion way to test the effect of student experiments. After experiment class, there are some questions given in the experimental report template. These problems are more difficult and more open than the preview problem, and further deepen the students' understanding of the experiment.

TABLE I. THE COMPARISON BETWEEN "MICRO-CLASSROOM + EXPERIMENTAL SUPERMARKET" TEACHING MODE AND THE TRADITIONAL COLLEGE PHYSICS EXPERIMENT CLASS MODE

\begin{tabular}{|c|c|c|c|}
\hline & Before the experiment & Into the laboratory & After the experiment \\
\hline $\begin{array}{l}\text { Traditional } \\
\text { class mode }\end{array}$ & $\begin{array}{l}\text { According to the experimental } \\
\text { guidance booklet, the students } \\
\text { write the experimental preview } \\
\text { report. }\end{array}$ & $\begin{array}{l}\text { The teacher explain in detail the } \\
\text { experimental principle, } \\
\text { demonstrate the experimental } \\
\text { operation process; according to the } \\
\text { teacher requirements, the students } \\
\text { do the experiment step by step. }\end{array}$ & $\begin{array}{l}\text { Data processing, the } \\
\text { students complete the } \\
\text { experimental report. }\end{array}$ \\
\hline $\begin{array}{l}\text { Experimental } \\
\text { supermarket } \\
\text { mode }\end{array}$ & $\begin{array}{l}\text { Independent selection of } \\
\text { experimental projects, with } \\
\text { reference to the experimental } \\
\text { instructions and experimental } \\
\text { principles, experimental } \\
\text { equipment and other micro-video } \\
\text { to understand the contents of the } \\
\text { experiment, to complete the } \\
\text { experimental preview report } \\
\text { according to the questions given } \\
\text { for preview. }\end{array}$ & $\begin{array}{l}\text { Instructors check the preview } \\
\text { effect, and students answer the } \\
\text { preview questions. students begin } \\
\text { to do experiments, when they meet } \\
\text { the requirements for preview. }\end{array}$ & $\begin{array}{l}\text { Teacher questions or } \\
\text { group discussions, to } \\
\text { test the experimental } \\
\text { results; complete the } \\
\text { experimental reports } \\
\text { after class. }\end{array}$ \\
\hline
\end{tabular}

\section{CONCLUSIONS}

The "micro-classroom + experimental supermarket" teaching mode aims for cultivate the students' autonomous learning ability. Compared with the traditional experimental teaching mode, it can give the students more autonomy, greatly improve the efficiency of experimental preview, ensure the time for autonomous exploration during the experiments, and deepen the understanding of the purposes and experimental principles of the experiment. After more than two years' practice, the teaching mode has been recognized by the majority of teachers and students in our university. Of course, there are some uncertainties in the implementation of the teaching process, for example, the examination of students' preview effect, the classroom management in the group discussion process, so the teachers should continue to improve the teaching mode. 


\section{ACKNOWLEDGMENT}

This research has been supported by the Foundation of Teaching and Research of University of Jinan (No. JZ1602).

\section{REFERENCES}

[1] K.Fang , J.Lv , and X.Ch.Ma, "The Realization and Research of Mobile Learning Micro-lecture System in College Physics Experiment Course ," Physics and Engineering. J. vol. 26(2), pp. 65-71, 2016.

[2] X.Wu, J.W.Xiong, "Study on college physics experiment teaching mode and supporting platform based on flipped classroom, " Physics Experimentation. J. vol. 35(10), pp.11-14,2015.

[3] X.Qian, X.H.Yang, "Probing into the cultivation of practical capability and innovation capability of college students by the college physics experiment from the point of view of solving problem,'Physics and Engineering. J. vol. 25(3), pp. 73-76, 2015.

[4] H.K.Zhang, M.H.Shao and X.J.Cui, Physics Experiment of College, Higher Education Press,Beijing, pp. 63-70, 2015.

[5] X.X.Zhang, S.H.Wang and S.H.Zhang, "The reform of college physics experiment preview mode based on MOOC education idea ," Physics Experiment of College. J. vol.29(3),pp. 104-108,2016.

[6] Y.Li, M. "Exploration on the reform of digital teaching in college physics experiment," Physics Experiment of College. J. vol.29(4),pp.104-108,2016. 